\title{
A review of municipal solid waste in China: characteristics, compositions, influential factors and treatment technologies
}

\author{
Yanli Zhu ${ }^{1} \cdot$ Youxian Zhang ${ }^{1} \cdot$ Dongxia Luo $^{1} \cdot$ Zhongyi Chong $^{2} \cdot$ Erqiang Li $^{1}$. \\ Xuepeng Kong ${ }^{1}$
}

Received: 14 February 2019 / Accepted: 19 August 2020 / Published online: 9 September 2020

(C) The Author(s) 2020

\begin{abstract}
Municipal solid waste (MSW) severely threatens human health and the ecological environment owing to its toxicity, mutagenic activity and carcinogenicity. The continuous increase in MSW together with stringent regulations makes sanitary disposal imperative. Waste sorting and recycling has been recognized as an efficient and economical treatment strategy. By analysing research data from 31 provinces between 2000 and 2017, the overarching goal of this work was to determine the characterizations and the compositions of MSW in China and then provide advices for sorting, transporting, storing and disposing of MSW. The results showed that the amount of MSW that was generated ranged from 0.08 to $2.34 \mathrm{~kg} \mathrm{~d}^{-1} \mathrm{ca}^{-1}$ and averaged $0.73 \mathrm{~kg} \mathrm{~d}^{-1} \mathrm{ca}^{-1}$ in China. The average bulk density, moisture content and the wet basis of the low calorific value of the MSW were $325 \mathrm{~kg} \mathrm{~m}^{-3}$, $50.3 \%$ and $4649 \mathrm{kcal} \mathrm{kg}^{-1}$. The MSW in China could be classified into four main categories, food waste, recycling waste, landfill waste and hazardous substances, and could be further classified into ten sub-categories. Overall, food waste was the most common and could be best managed via compost production. Bulk density was highly positively correlated with the ratio of the dust and bricks in all MSW and highly negatively correlated with the ratio of the food waste, metal, glass, plastic and rubber. The wet basis of the low calorific value was highly positively correlated with the ratio of the plastic and rubber, and the water content was highly positively correlated with the ratio of the food waste. Temporally, most of the components, especially waste paper and plastics, increased, while wood, dust and bricks decreased.
\end{abstract}

Youxian Zhang

zhuyl18@lzu.edu.cn

1 College of Earth and Environment, Lanzhou University, Lanzhou 730000, China

2 Sound Resource and Environment Company, Beijing 100010, China 


\section{Graphic abstract}

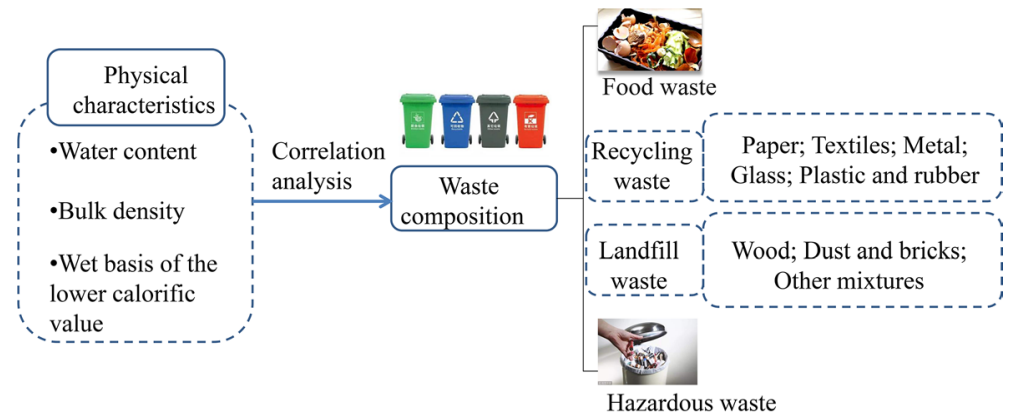

Overall flow diagram of the paper

Keywords Municipal solid waste $\cdot$ Compositions $\cdot$ Characterizations $\cdot$ Treatment technologies

\section{Introduction}

Municipal solid waste (MSW) is a heterogeneous waste stream that is an inevitable part of daily life and can seriously damage the environment and human health (Tian et al. 2012; Hou et al. 2012). With a population of $13.8 \times 10^{2} \mathrm{M}$ and a vast territory covering $96 \times 10^{2} \mathrm{~K} \mathrm{~km}^{2}$ (NBSC 2017), China is the largest developing country and deserves special attention regarding MSW. The amount of collected MSW and the population in five recent years in China are presented in Fig. 1. The amount of MSW collected in China was over 2 billion $\mathrm{t}$ in 2016, and the amount continues to increase.

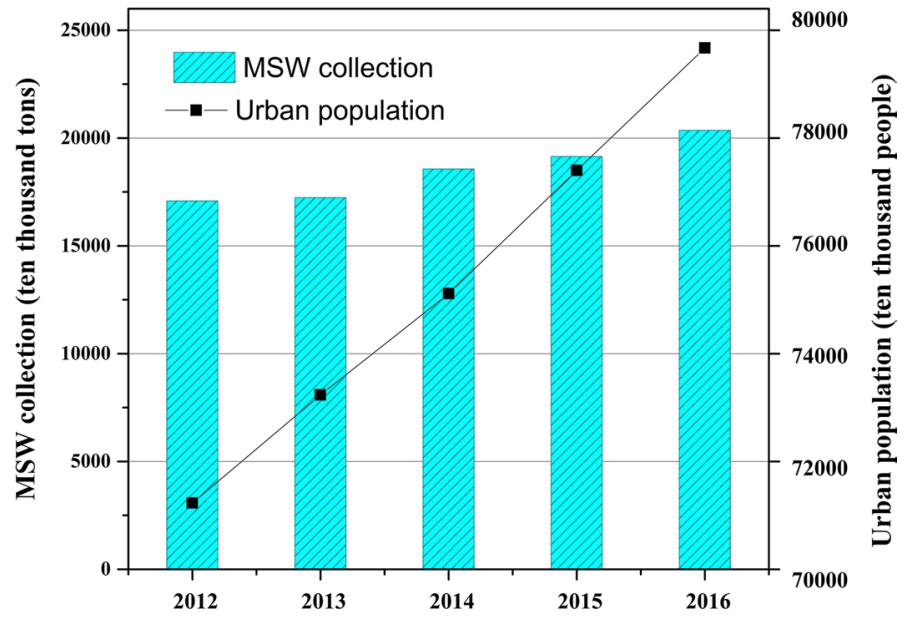

Fig. 1 The collected MSW and population in five recent years in China (China National Bureau of Statistics, 2019) 
To better address this situation, China has made great efforts to recycle valuable wastes and reduce the amount of MSW that would be disposed of in landfills and incinerated. For instance, the MSW harmless treatment capacity increased by 252 (from 2107 $\mathrm{t} / \mathrm{d}$ in 1980 to $533,455 \mathrm{t} / \mathrm{d}$ in 2014), and the number of non-polluting disposal plants increased by a factor of 47 (in 1980: 17 units; in 2014: 818 units) (Gu et al. 2017). New regulations, measures (PRC 2017) and notices promoting the sorting of MSW in some cities (PRC 2018) have also been implemented in the past few years. However, the efforts to manage MSW have fallen far behind the increase in MSW.

Due to various lifestyle choices, economic situations and family structures, the amount and quality of MSW vary drastically from district to district (Abdel-AbdelShafy and Mona 2018). The factors that influence MSW are summarized in Fig. 2 (Han et al. 2018). Knowing the quantity, composition and characteristics of MSW is critical for appropriately handling and managing these wastes. Based on the generation rate, bulk density and moisture content, an administrator can decide the trash placement, transport turnover time and even MSW disposal technology used.

Although a number of published papers have reviewed the trends in MSW generation and the corresponding composition in China, these studies have mainly focused on specific aspects of MSW management in specific cities. This paper attempts to review the overall MSW situation in China and research the relationship between physical characteristics and the MSW composition. With this overall goal, this paper seeks to (i) evaluate the MSW generation, characterization and composition in China; (ii) discuss the relationships between various characteristics and the composition; and (iii) discuss the treatment technologies of MSW in China.

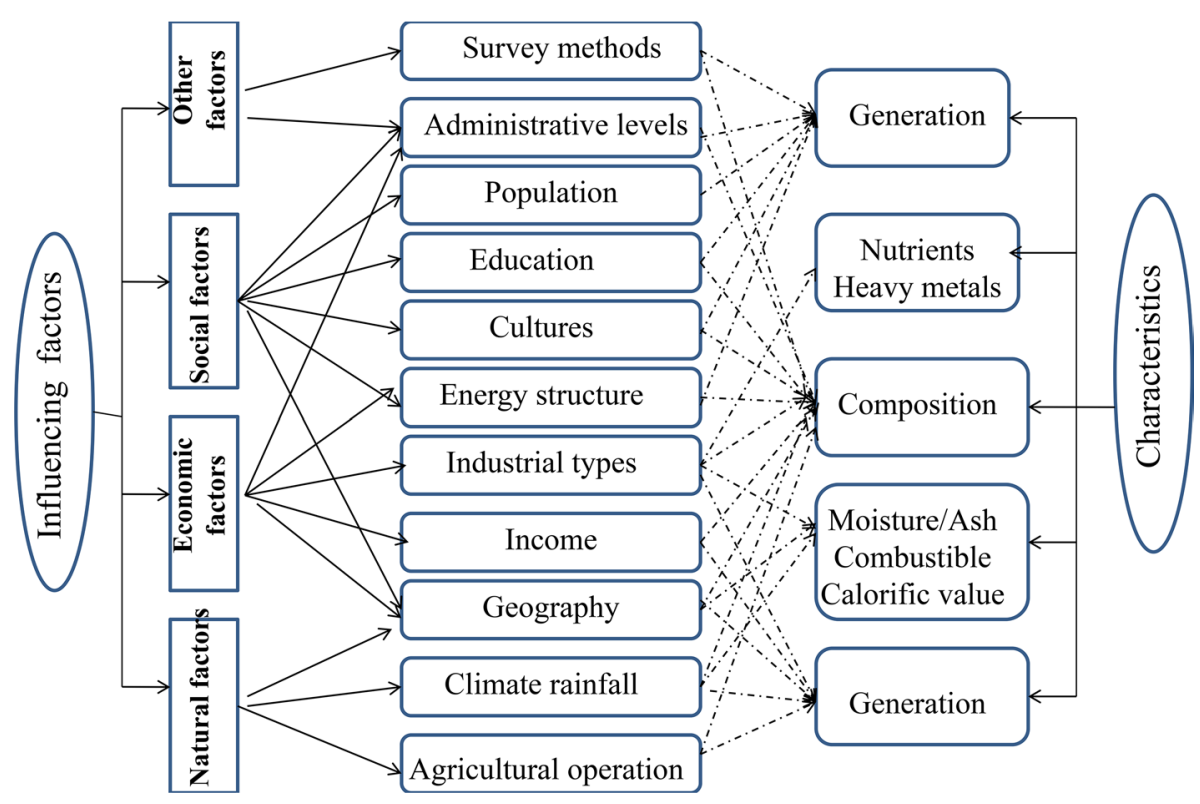

Fig. 2 Factors that influence MSW (Han et al. 2018) 


\section{Methods}

A standard literature search was performed using two pertinent search engines for scientific and academic research, the China National Knowledge Internet (2019) and the VIP Chinese Science and Technology Internet (2019). These search engines store China's largest citation databases. The search dates were 2000-2017.

\section{Generation rate}

MSW is usually generated from households, markets and commercial areas in developing countries. The generation rate in China is $0.73\left(\mathrm{~kg} \mathrm{~d}^{-1} \mathrm{ca}^{-1}\right)$, approximately equal to the result of another study, $0.76\left(\mathrm{~kg} \mathrm{~d}^{-1} \mathrm{ca}^{-1}\right)$ (Yue et al. 2013). The main investigation method used by researchers involved providing plastic bags to residents via a door-to-door approach. The solid waste produced in outdoor common areas was not considered, and therefore, the statistical results may be lower than the actual values.

As Table 1 shows, the districts with the highest production rates in China were in the central areas, followed by those in the southern areas, northern areas, northeastern areas, eastern areas, northwestern areas and southwestern areas. The MSW production rate was influenced by the economic development level, average family size, monthly income and employment status. The eastern areas of China have a higher economic development rate and therefore a higher MSW generation rate than other areas. However, more data were collected in Anhui, Fujian and Jiangxi Provinces in this work due to the limitations of the data collection method; as a result, the overall production rate was lower $\left(0.58 \mathrm{~kg} \mathrm{~d}^{-1} \mathrm{ca}^{-1}\right)$ than previously estimated, and the result in the eastern area was lower than the results in the northeastern, northern, southeastern and central areas. Excluding Anhui Province $\left(0.41 \mathrm{~kg} \mathrm{~d}^{-1} \mathrm{ca}^{-1}\right)$, the average generation rate in the eastern area was $0.65 \mathrm{~kg} \mathrm{~d}^{-1} \mathrm{ca}^{-1}$. Based on the economic development level, China can also be divided into four areas: the northeastern area (Liaoning, Jilin and Heilongjiang Provinces), eastern area (Beijing, Tianjin, Hebei, Shanghai, Jiangsu, Zhejiang, Fujian, Shandong, Guangdong and Hainan), central area (Shanxi, Anhui, Jiangxi, Henan, Hubei and Hunai Provinces) and western area (Neimenggu, Guangxi, Chongqing, Sichuan, Guizhou, Yunnan, Xizang, Shanxi, Gansu, Qinghai, Ningxia and Xinjiang). The average MSW generation rates in the northeastern, eastern, central and western areas were $0.93,0.87,0.64$ and $0.46 \mathrm{~kg} \mathrm{~d}^{-1} \mathrm{ca}^{-1}$, in agreement with the economic levels. Table 2 compares the MSW production rates in China with those in other countries. The MSW production rate in China was higher than those in India, Bangladesh, Iran and Nigeria but lower than those in Brazil.

The frequency of the samples is presented in Fig. 3. Approximately $70 \%$ of the samples had values lower than $1\left(\mathrm{~kg} \mathrm{~d}^{-1} \mathrm{ca}^{-1}\right)$. The generation rate usually increased in summer and during holiday periods (Rafiee et al. 2018). Most fruits (such as watermelon, peaches and litchi) are commonly consumed in summer, which increases the amount of peel waste as well as the water content and organic content in the southern area. Important holidays such as the Spring Festival increased household consumption and resulted in more waste being generated (including paper, plastic, rubber, metal cans and other materials) in China. 


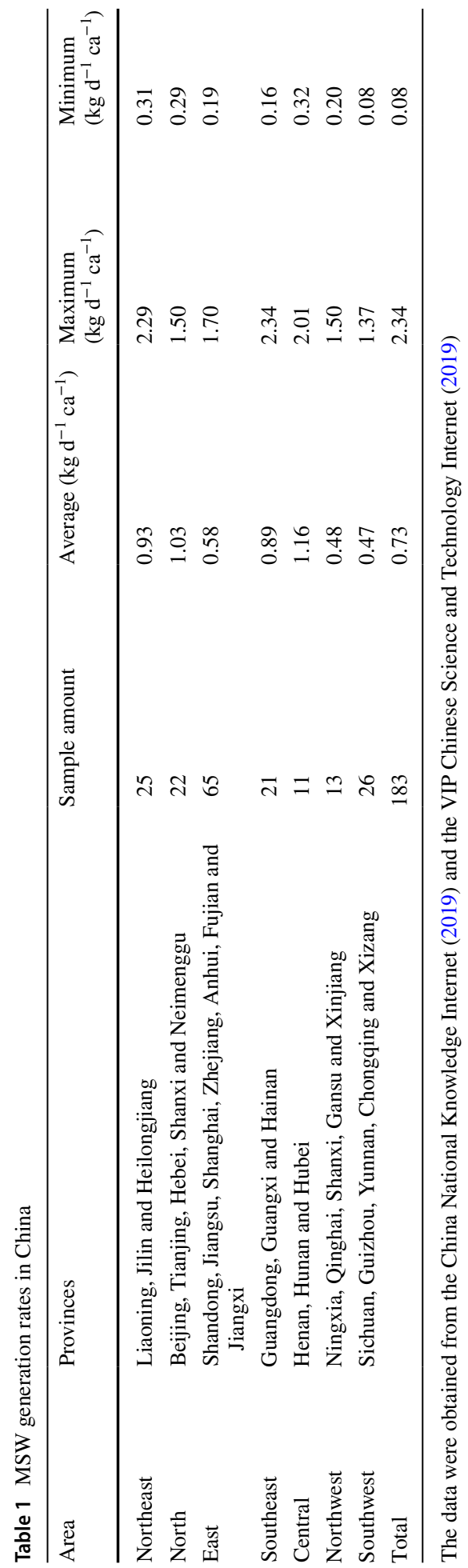


Table 2 MSW production rate compared with the findings of other authors

\begin{tabular}{lll}
\hline Country & $\begin{array}{l}\text { Production rate } \\
\left(\mathrm{kg} \mathrm{d}^{-1} \cdot \mathrm{ca}^{-1}\right)\end{array}$ & References \\
\hline Brazil & 1.06 & De et al. (2017) \\
India & 0.46 & Mufeed et al. (2008) \\
Bangladesh & 0.38 & Islam (2018) \\
Iran & 0.26 & Hassan et al. (2016) \\
Nigeria & 0.17 & Sha'Ato et al. (2007) \\
Australian & 1.8 & Hla and Daniel (2015) \\
\hline
\end{tabular}

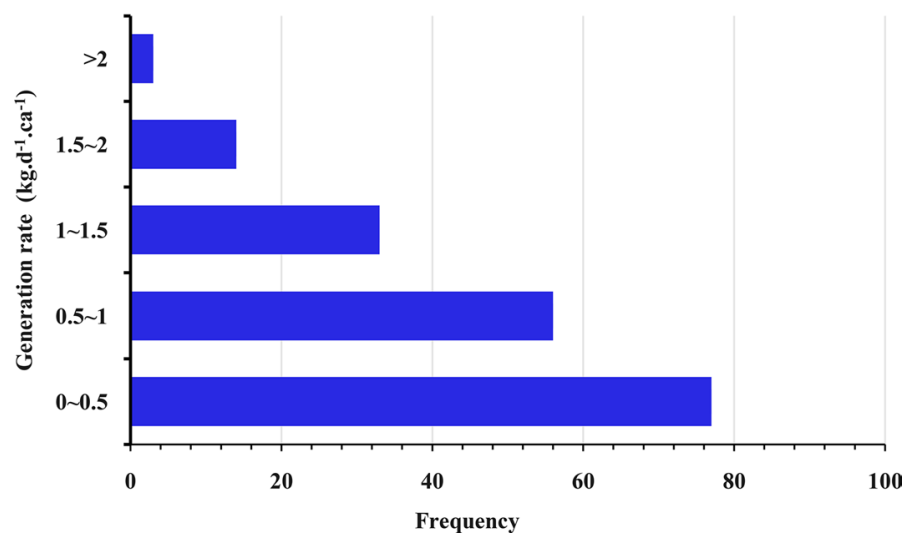

Fig. 3 Frequencies of the MSW generation rates in China

\section{Physical characteristics}

\subsection{Bulk density}

The bulk density reflects the compression degree of MSW. A relatively low volume weight indicates better compressibility and also indicates a low content of inorganic minerals. Inorganic minerals are harmless to the human living environment compared to other types of garbage. Therefore, low volume weight indicates real wastes that influence visual beauty and are harmful to human health were transported and disposed of elsewhere. Furthermore, when collecting and transporting a certain amount of garbage, due to the high compressibility of garbage with a low volume weight, few vehicles are needed. These factors result in a relatively high economic-environmental benefit. As presented in Table 3, the bulk density of MSW was lowest in the northern area, and that in the southwestern area was the highest in China, likely due to the lower rainfall amount in the northern area and higher rainfall amount in the southwestern area. The rainfall amount affects the water content, which may further influence the bulk density. The MSW composition is another factor that contributes to the bulk density. A relatively low water content and high percentage of light waste may lead to a low volume weight. The accurate determination of density is a critical criterion for obtaining exact estimations of storage, collection, transportation and landfill capacities in any waste management programme. Approximately $70 \%$ of the bulk density samples were in the range of 
Table 3 The bulk density of MSW in China

\begin{tabular}{lcllc}
\hline Area & Sample amount & $\begin{array}{l}\text { Average } \\
\left(\mathrm{kg} \mathrm{m}^{-3}\right)\end{array}$ & $\begin{array}{l}\text { Maximum } \\
\left(\mathrm{kg} \mathrm{m}^{-3}\right)\end{array}$ & $\begin{array}{l}\text { Minimum } \\
\left(\mathrm{kg} \mathrm{m}^{-3}\right)\end{array}$ \\
\hline Northeast & 8 & 251 & 310 & 110 \\
North & 2 & 167 & 192 & 142 \\
East & 10 & 212 & 291 & 72 \\
Southeast & 8 & 354 & 493 & 220 \\
Central & 2 & 225 & 280 & 169 \\
Northwest & 10 & 325 & 345 & 301 \\
Southwest & 27 & 400 & 650 & 74 \\
Total & 67 & 325 & 650 & 72 \\
Iran $^{\mathrm{a}}$ & & 211 & 232 & 184 \\
Nigeria $^{\mathrm{b}}$ & & 287 & 337 & 249 \\
Algeria $^{\mathrm{c}}$ & & 360 & & \\
\hline
\end{tabular}

${ }^{\mathrm{a}}$ Hassan et al. (2016), ${ }^{\mathrm{b}}$ Sha'Ato et al. (2007), ${ }^{\mathrm{c}}$ Guermoud et al. (2009)

100-400 $\mathrm{kg} \mathrm{m}^{-3}$, as shown in Fig. 4, meaning that the MSW in China has relatively high compressibility.

\subsection{Water content}

As shown in Table 4, the average water content of MSW in China was 50.3\%. The water content of MSW is most affected by the ratio of food waste because the water content of food waste can reach $60-70 \%$; the other fractions, such as paper, metal and glass, were lower than 30\% (Hla and Daniel 2015). Climate, especially the amount of precipitation, can also influence the water content. The food waste levels in the eastern, southeastern and central areas in China were significantly higher than those in the other regions, which led to the higher MSW water content in those regions. The water content plays a significant

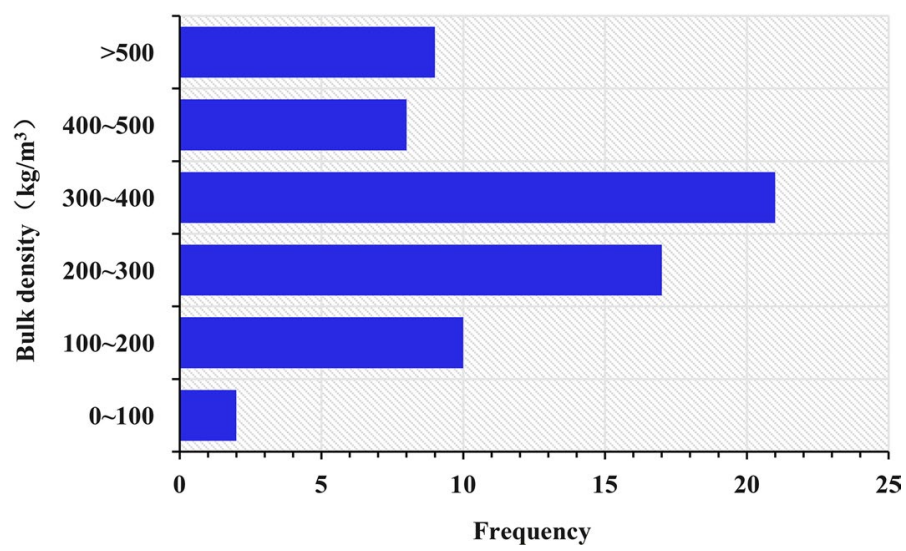

Fig. 4 Frequencies of the bulk density of MSW in China 
Table 4 Water content of MSW in China

\begin{tabular}{lclll}
\hline Area & Sample amount & Average (\%) & Maximum (\%) & Minimum (\%) \\
\hline Northeast & 14 & 42.5 & 76.8 & 6.8 \\
North & 12 & 43.7 & 61.2 & 24.9 \\
East & 44 & 60.0 & 86.3 & 32.7 \\
Southeast & 27 & 54.3 & 70.2 & 39.2 \\
Central & 4 & 50.8 & 61.8 & 38.1 \\
Northwest & 11 & 44.4 & 52.4 & 37.2 \\
Southwest & 65 & 45.9 & 76.2 & 18.8 \\
Total & 177 & 50.3 & 86.3 & 6.8 \\
Australia $^{\mathrm{a}}$ & & 49.5 & - & - \\
Taiwan $^{\mathrm{b}}$ & & 55.6 & - & - \\
India $^{\mathrm{c}}$ & & 42.05 & - & - \\
Algeria $^{\mathrm{d}}$ & & 58.9 & - & - \\
\hline
\end{tabular}

${ }^{\mathrm{a}} \mathrm{Hla}$ and Daniel (2015), ${ }^{\mathrm{b}}$ Chang et al. (2007), ${ }^{\mathrm{c}}$ Kumar and Goel (2009), ${ }^{\mathrm{d}}$ Guermoud et al. (2009)

role in determining the calorific value of MSW (Komilis et al. 2014). As shown in Fig. 5, approximately $70 \%$ of the water contents of the samples ranged from 30-60\%.

\subsection{Wet basis of the low calorific value}

Accounting for the energy content is essential in the design and operation of any type of thermochemical conversion system, and the energy content can be described based on high or low heating values, which can be measured on a dry or wet basis. Notably, the wet basis of the low calorific value $\left(\mathrm{LCV}_{\mathrm{wb}}\right)$ has been recommended for calculating the energy content of waste in practical applications (Hla and Daniel 2015), and the value can be predicted based on the results of physical and chemical analyses. Chang et al. (2007) developed two predictive models using a multiple regression analysis; the coefficients were 0.983 and 0.975 . Guermoud et al. (2009) calculated LCV $_{\text {wb }}$ by measuring high calorific values, total moisture and total hydrogen.

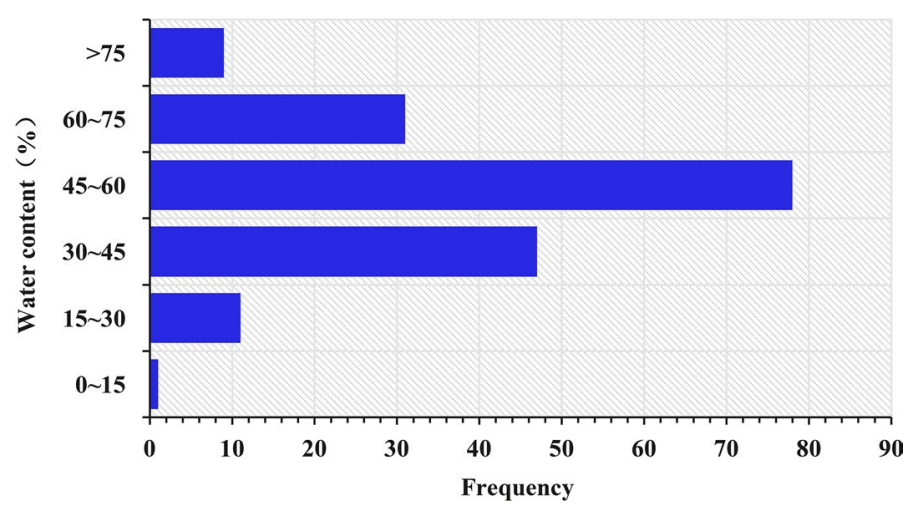

Fig. 5 Frequencies of the water content of MSW in China 
Table 5 Wet basis of the low calorific value $\left(\mathbf{L C V} \mathbf{w b}_{\mathbf{w b}}\right)$

\begin{tabular}{|c|c|c|c|c|}
\hline Area & Sample amount & $\begin{array}{l}\text { Average } \\
\left(\mathrm{kcal} \mathrm{kg}^{-1}\right)\end{array}$ & $\begin{array}{l}\text { Maximum } \\
\left(\mathrm{kcal} \mathrm{kg}^{-1}\right)\end{array}$ & $\begin{array}{l}\text { Minimum } \\
\left(\mathrm{kcal} \mathrm{kg}^{-1}\right)\end{array}$ \\
\hline Northeast & 7 & 3586 & 4491 & 2280 \\
\hline North & 5 & 3541 & 5211 & 2159 \\
\hline East & 9 & 4209 & 5800 & 2318 \\
\hline Southeast & 16 & 4435 & 8272 & 3056 \\
\hline Central & 4 & 2692 & 4607 & 1687 \\
\hline Northwest & 10 & 6182 & 9447 & 4602 \\
\hline Southwest & 32 & 5050 & 11,784 & 2078 \\
\hline Total & 83 & 4649 & 11,784 & 1687 \\
\hline Australia $^{a}$ & & 7900 & & \\
\hline Taiwan $^{\mathrm{b}}$ & & 1434 & & \\
\hline India $^{c}$ & & 2391 & & \\
\hline Algeria $^{\mathrm{d}}$ & & 1028 & & \\
\hline
\end{tabular}

${ }^{\mathrm{a}} \mathrm{Hla}$ and Daniel (2015), ${ }^{\mathrm{b}}$ Chang et al. (2007), ${ }^{\mathrm{c}}$ Kumar and Goel (2009), ${ }^{\mathrm{d}}$ Guermoud et al. (2009)

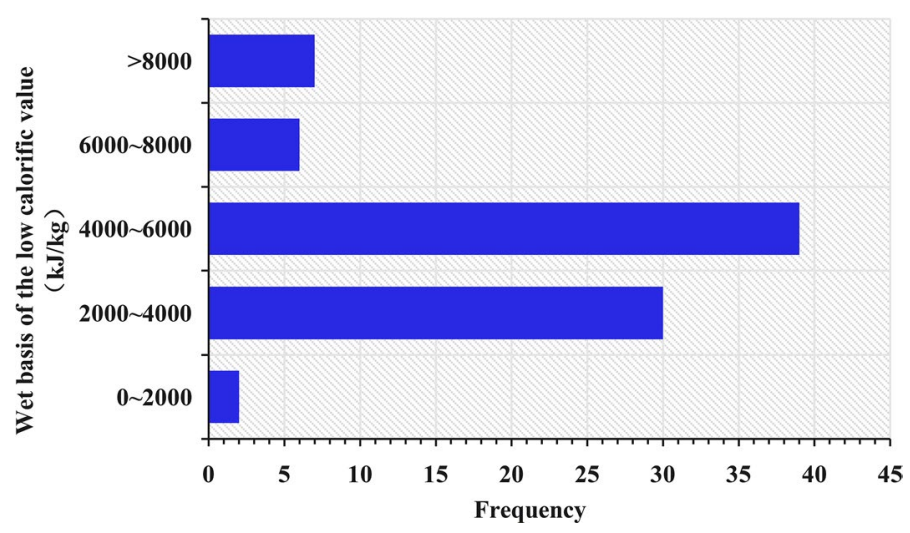

Fig. 6 Frequencies of the wet basis of the low calorific value of MSW in China

As shown in Table 5, the average $\mathrm{LCV}_{\mathrm{wb}}$ in China was $4649\left(\mathrm{kcal} \mathrm{kg}^{-1}\right)$. The $\mathrm{LCV}_{\mathrm{wb}}$ values in the northwestern and southwestern areas were relatively high, which may have been related to the low water content and high plastic ratio in those regions (Chang et al. 2007). As shown in Fig. 6, the energy content greater than $70 \%$ of the samples ranged from 2000-6000 kcal kg-1.

\section{Physical composition}

The composition of MSW is related to the geographic region, population, social conditions and people's eating habits, as well as the predominant economic activities and even the season of the year (Campuzano and Simón 2016). As various original sources 
noted, MSW is heterogeneous, resulting in difficulties in sorting and utilizing the corresponding material. Therefore, sorting MSW is necessary before any meaningful treatment process.

As presented in Table 6, MSW was classified into four broad groups based on the Chinese MSW sorting policy. Approximately half of MSW is food waste (47.7\%), followed by recycling waste $(26.7 \%)$ and landfill waste $(24.9 \%)$. Recycling waste refers to paper, textiles, metal, glass, plastic and rubber. Hazardous waste should be collected and transported alone due to the potential environmental effects, although this type of waste accounted for less than $1 \%$ of all MSW. The recycling waste ratio value may be higher in practice than observed here, as research on sorting has ignored the effect of rag pickers and the fact that some wastes are unusable. Rafiee et al. (2018) revealed the impact of various festivals and events on the recycling potential of municipal solids, and the results showed that important national anniversary festivals and wedding days were associated with notable increases in the generation of recyclable fractions. Additionally, the tipping fees at disposal sites, regulatory factors, the number of recycling companies and financial support have significant influences on the recovery rate of recycling wastes.

For further analysis, the four broad groups of MSW were classified into ten subdivisions, including food waste, paper, textiles, metal, glass, plastic and rubber, wood, dust and bricks, hazardous waste and other mixtures. Among them, food waste was the most common, followed by dust and bricks, and plastic and rubber. In this work, food waste was mainly generated from households, and restaurants were not included.

As shown in Table 7, over time, with increasing incomes and quality of life, the composition of MSW has changed. Paper and plastic waste have increased in the past few years, while wood and dust waste have decreased.

Comparing the physical composition of MSW in China with that in other countries, China had a higher percentage of dust and bricks in its MSW than did other countries (Table 8). Table 9 compares the results of this work with other reports, and the perceptions of the waste subdivisions were similar.

\subsection{Food waste}

Food waste is produced from the processing, cooking, distribution, production and consumption of food. Dietary habits may be the main reason for food waste distributions. Campuzano and Simón (2016) conducted a review showing that the average humidity, carbon content and nitrogen content of food waste were $72.8 \pm 7.6 \%, 46.6 \pm 4.4 \%$ and $2.9 \pm 0.6 \%$, respectively. Thi et al. (2015) found that food waste contained 74-90\% moisture and had a volatile solids-to-total solids ratio (VS/TS) of $80-97 \%$ and a C/N ratio of 14.7-36.4. AbdelShafy et al. (2018) revealed that food waste was rich in proteins, minerals and sugars that could be used in other processes as substrates or raw materials, including in composting and anaerobic digestion. Adequate aeration (0.2-0.6 $\mathrm{L} \mathrm{min}^{-1} \mathrm{~kg}^{-1}$ organic matter (OM)) (Zhang et al. 2016), a proper C/N ratio (20-40) (Maulini-Duran et al. 2014) and the specific particle size (Zhang and Sun 2016) are crucial variables to consider when composting. Process control parameters, such as temperature and the number of turns, also influence the final compost. Pretreatment methods (physical pretreatments or biological pretreatments) and the inhibition and mitigation of ammonia and volatile fatty acids affect the stability and sustainability of anaerobic digestion, thus influencing the yield of biogas (Ren et al. 2018). 


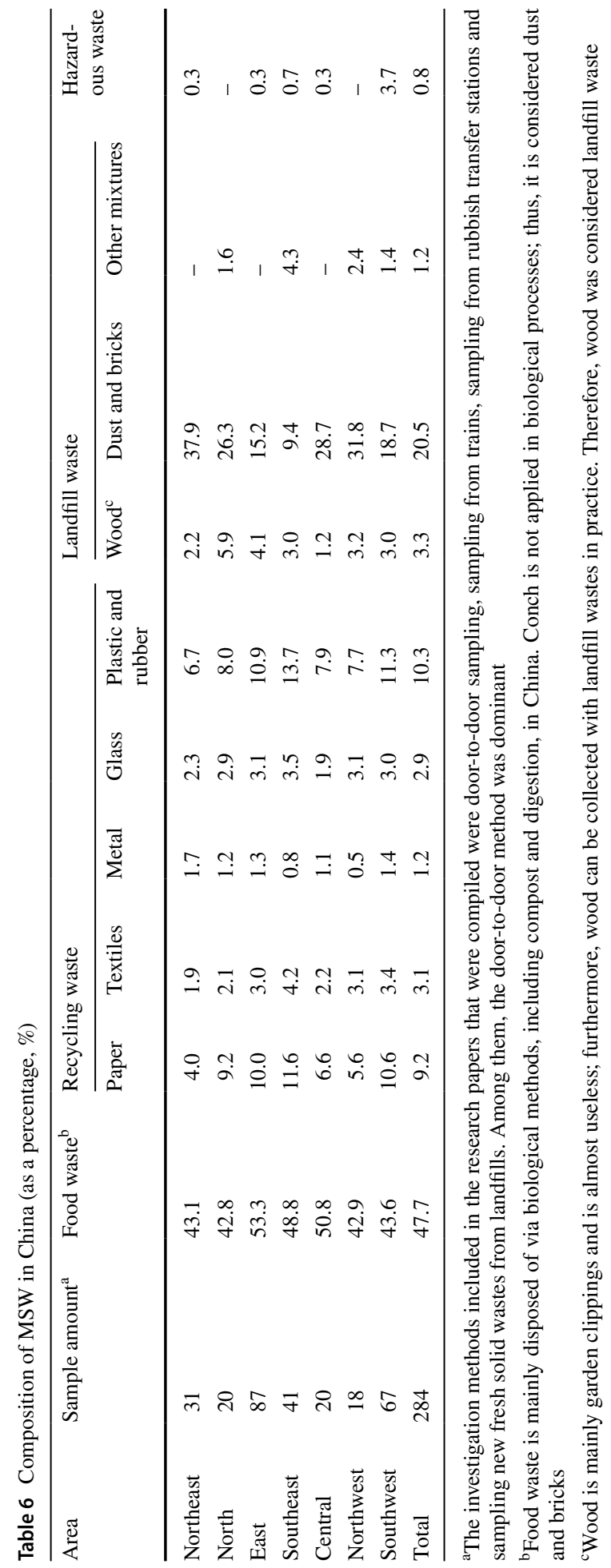




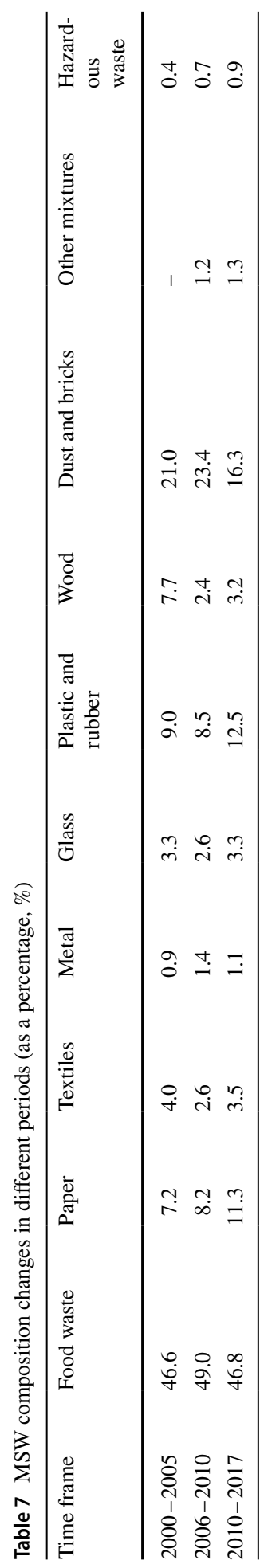




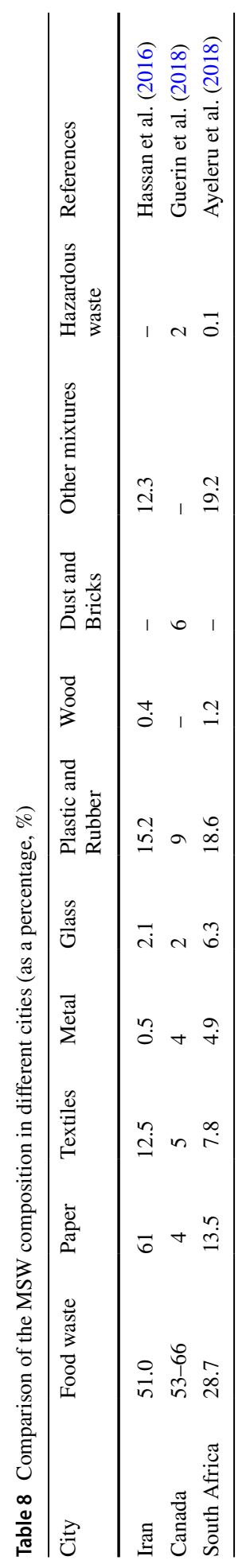




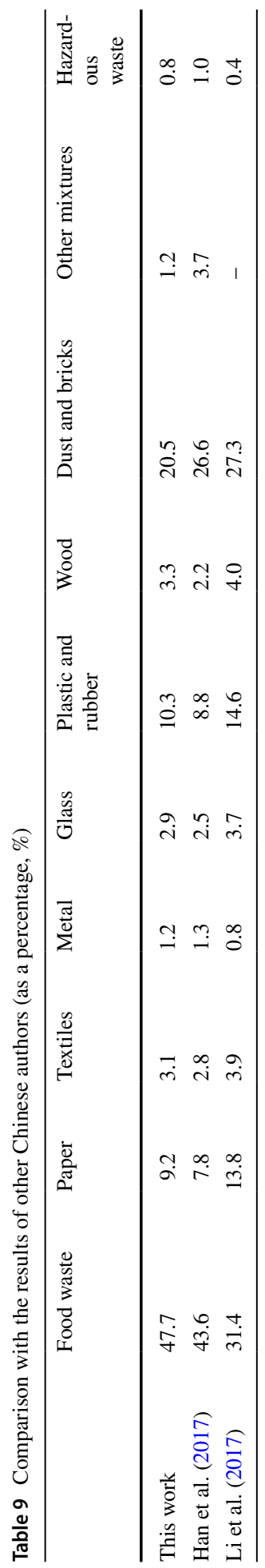




\subsection{Plastic waste}

Rag pickers play a key role in some Chinese cities. These people work day and night to collect recyclable materials from streets, bins and disposal sites for their livelihood, and only a small quantity of recyclable materials remains when they are finished. In China, approximately $60-80 \%$ of plastic waste is recycled, compared to $10-15 \%$ in developed nations worldwide. The plastic from household waste contains numerous immiscible polymers, product types and product designs (e.g. colours and polymer separability levels), which often lead to considerable physical losses during sorting and low-quality recycled plastic (Eriksen and Astrup 2019). PET, PE, PP and PS are the predominant polymer types found in household waste. These materials are immiscible and must be separated from each other before they can be recycled into new raw materials.

\subsection{Paper}

Paper, such as newspapers, cardboards, magazines and books, is also a main class of MSW, accounting for $9.15 \%$ of all MSW. Most paper products are generally composed of low-grade mixed paper that contains a relatively high unusable content, which ends up as waste. This issue will intensify as the recycling rate increases, since paper fibres become too short for paper-making after six reuses. Approximately $6 \%$ of recycled paper fibres may be unusable for paper-making when the recycling rate reaches $50 \%$, but nearly $20 \%$ could be unusable if the recycling rate reaches $75 \%$ (Hou et al. 2012). Due to the prevalence of online shopping in China, the percentage of paper waste will likely increase in the future. Taking advantage of express delivery companies, packaging cartons can be collected in a better way.

As some paper samples are in contact with materials with high moisture contents, such as food residue, the average moisture level of paper is generally higher than that of pure paper. The ranges of the $\mathrm{C}, \mathrm{H}$ and $\mathrm{O}$ contents of paper were $33.5-43.7 \%, 4.86-6.8 \%$ and $34.7-47.8 \%$, which were similar to the content of cellulose $\left(\left(\mathrm{C}_{6} \mathrm{H}_{10} \mathrm{O}_{5}\right)_{n}\right)$, a primary constituent of paper (Komilis et al. 2012).

\subsection{Hazardous substances}

Although hazardous substances (HSs), including some batteries, paints, mercury-containing waste, pharmaceuticals, vehicle maintenance products and many other products, have a relatively small volume, they can lead to significant environmental problems. These environmental problems affect the soil, air and water which are associated with humans and living creatures. These materials have explosive, flammable, oxidizing, infectious, radioactive and corrosive properties (Muralikrishna and Manickam 2017). The definition of HS is unclear (Halstenberg et al. 2018), which is confusing for the government and populace. A collectively exhaustive classification system should be established to help people gain a quick and precise understanding of HSs and avoid mistakes resulting from imprudent behaviour.

In China, HSs refer to solid wastes with hazardous characteristics that are listed in the national HSs list or have been identified according to the national HSs identification standards and identification methods (National Hazardous Waste List 2016). Hazardous characteristics refer to corrosivity, toxicity, ignitability, reactivity and infectivity. 
The following clause was included in an executive order: waste medicines and their packaging, waste insecticides and disinfectants with their packaging, waste paints and solvents with their packaging, waste mineral oils and their packaging, waste film and waste paper, waste fluorescent tubes, waste thermometers, waste sphygmomanometers, waste nickel-cadmium batteries, mercury oxide batteries, and electronic hazardous wastes may not be managed in accordance with HSs. However, if the wastes listed in the preceding paragraph are sorted and collected from domestic garbage, they can be transported, stored, utilized or disposed of as HSs. The collection process, from resident housing to storage, may not be managed in accordance with HSs. The management of hazardous waste adopts an application and approval mechanism.

\section{Correlation analysis}

SPSS software (IBM SPSS Statistics 19) was used to analyse the relationships among the physical characteristics and physical compositions. As shown in Table 10, the volume weight was highly positively correlated with dust and bricks and other mixtures, inversely shows highly negatively correlated with food waste, metal, glass, plastic and rubber. The wet basis of the low calorific value was highly positively correlated with plastic and rubber and negatively correlated with textiles. The water content was highly positively correlated with food waste and highly negatively correlated with metal, dust and bricks.

\section{Recommendations}

MSW collection and disposal is one of the major environmental problems in most worldwide countries. MSW management solutions must be financially sustainable, technically feasible, socially, legally acceptable and environmentally friendly. It is effective to sort MSW at the source combined with material recycling, and the waste-to-energy generation method is a promising approach. As summarized in this study, food waste is the primary component of MSW. There should be more trash cans, vehicles and treatment facilities to collect food waste than there are for other waste. The frequency of transport should also be modified to prevent odour production.

Landfills, which involve high costs and limited life spans, are built in every county town in China. With the development of the urban-rural integration policy in China, a large amount of waste goes into landfills, causing capacity shortages. Based on the generation amount and characteristics of food waste, the decentralized construction of compost stations in remote regions is the best way to solve this dilemma. On the one hand, this practice can reduce the amount of MSW that is transported, reduce operation costs and extend landfill life; on the other hand, manure can be produced for soil bioremediation (Cerda et al. 2018). However, the source separation of the organic fraction of MSW is a key process that reduces the non-organic content in biowaste; thus, impurities such as heavy metals and pesticides can be contained in the compost (Huerta-Pujol et al. 2010). Reducing the amount of food waste can also improve the energy content of MSW, which is beneficial to incineration. Moreover, it is obvious that building decentralized compost stations requires vast investments and relatively high operation fees. According to a survey conducted by the authors, approximately $350 \mathrm{RMB}$ is needed to treat $1000 \mathrm{~kg}$ of food waste, including fixed 


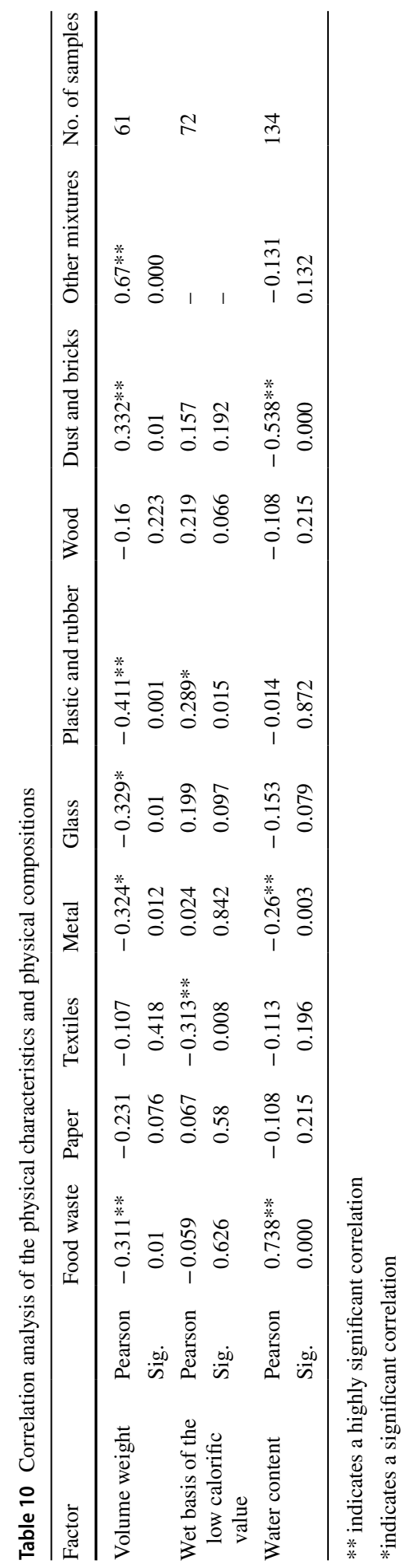


asset investments (trash bins, compost machines, workshops and transportation vehicles) and operation fees (staff salaries, electric charges and other fees).

Dust and bricks have low $\mathrm{C} / \mathrm{N}$ ratios and energy contents which are only disposed of in landfills. Dust and bricks pose little harm to the environment and can be abandoned in situ. Recycling wastes should be collected at regular intervals and classified when disposed of. In this work, approximately $26 \%$ of waste was recycling waste, but the value may be as low as $20 \%$ in practice. Notably, some materials are unusable due to impurities, and rag pickers decrease the amount of material that is collected. Plastics, textiles and paper represented $80 \%$ of recycling wastes. If these materials cannot be used again, they should be burned or incinerated for heat generation because they are essentially hydrocarbons. The average dry basis calorific values of plastics and paper are $39,350 \mathrm{kcal} \mathrm{kg}^{-1}$ and $15,129 \mathrm{kcal} \mathrm{kg}^{-1}$, respectively (Komilis et al. 2012). Collection, storage and transportation are bottlenecks for hazardous waste treatment systems (Dotoli and Epicoco 2017). Hazardous waste treatment involves a high cost due to its relatively low yield and potential negative environmental effect.

Systematic waste separation is a critical component of a successful integrated waste management system, and waste needs to be sorted at the source as much as possible to reduce the amount of waste required disposal of. More accessible recycling facilities and the use of colour-coded containers for designated waste types need to be provided and publicized to promote recycling behaviours. Improving the waste fee-levying system and increasing waste collection and disposal fees can recoup costs and raise funds for investments in new facilities. As the main category of MSW, food waste, with a high moisture content and organic fraction, should be managed via compost production. Local conditions differ considerably among Chinese cities, and thus, a one-size-fits-all solution would be ineffective. In southern China, food waste accounted for approximately 50\% of MSW; therefore, more compost facilities should be built in there than other areas. In the eastern area, the percentage of recycling waste was higher than that in other areas, therefore, more funds should be invested in recycling industries in there than other areas. In the northwestern area, the $\mathrm{LCV}_{\mathrm{wb}}$ of MSW was higher than that in other areas; therefore, more incineration facilities should be built.

The public, companies and government are the important players involved in MSW reduction, sorting and recycling. The government should provide colour-coded plastics for source separation and establish special funds to broadcast and encourage source separation. Sanitation companies should strengthen management to classify transportation and avoid mixed transportation. The members of the public should assist in source reduction and source separation.

\section{Conclusions}

It is necessary to obtain more accurate data on the characteristics and composition of MSW to successfully manage heterogeneous MSW. The results of the review conducted in this research indicated high variability that was caused by various factors. The generation amount, average density, moisture content and low calorific value of MSW exhibited distinct regional distributions. The compositional components of MSW, especially for the four broad groups, showed similar distributions. The physical characteristics and composition had some complicated connections. These findings provide valuable and important guidance for forecasting the trash density, determining the transport turnover 
time and developing MSW disposal technology for governments in different areas. It is important to build models considering the relevant characteristics, compositions and targeted measures in the future to implement reduction and recycling strategies.

Open Access This article is licensed under a Creative Commons Attribution 4.0 International License, which permits use, sharing, adaptation, distribution and reproduction in any medium or format, as long as you give appropriate credit to the original author(s) and the source, provide a link to the Creative Commons licence, and indicate if changes were made. The images or other third party material in this article are included in the article's Creative Commons licence, unless indicated otherwise in a credit line to the material. If material is not included in the article's Creative Commons licence and your intended use is not permitted by statutory regulation or exceeds the permitted use, you will need to obtain permission directly from the copyright holder. To view a copy of this licence, visit http://creativecommons.org/licenses/by/4.0/.

\section{References}

Abdel-Shafy, H., \& Mona, S. M. (2018). Solid waste issue: Sources, composition, disposal, recycling, and valorization. Egyptian Journal of Petroleum, 27(4), 1275-1290.

Ayeleru, O. O., Okonta, F. N., \& Ntuli, F. (2018). Municipal solid waste generation and characterization in the city of Johannesburg: A pathway for the implementation of zero waste. Waste Management, 79, 87-97.

Campuzano, R., \& Simón, G. M. (2016). Characteristics of the organic fraction of municipal solid waste and methane production: A review. Waste Management, 54, 3-12.

Cerda, A., Artola, A., Font, X., et al. (2018). Composting of food wastes: Status and challenges. Bioresource Technology, 248, 57-67.

Chang, Y. F., Lin, C. J., Chyan, J. M., et al. (2007). Multiple regression models for the lower heating value of municipal solid waste in Taiwan. Journal of Environment. Management, 85, 891-899.

China National Knowledge Internet. (2019). https://www.cnki.net.

De, S. M. A., Raquel, G., Alyne, M. C., et al. (2017). Municipal solid waste in Brazil: A review. Waste Management and Research, 35, 1195-1209.

Dotoli, M., \& Epicoco, N. (2017). A vehicle routing technique for hazardous waste collection. IFACPapers OnLine, 50, 9694-9699.

Eriksen, M. K., \& Astrup, T. F. (2019). Characterisation of source-separated, rigid plastic waste and evaluation of recycling initiatives: Effects of product design and source-separation system. Waste Management, 87, 167-172.

Gu, B. X., Suqin, H. K., Wang, Z. B., et al. (2017). Characterization, quantification and management of China's municipal solid waste in spatio temporal distributions: A review. Waste Management, 61, $67-77$.

Guerin, J. E., Maxime, C. P., Sylvain, L., et al. (2018). The importance of characterizing residual household waste at the local level: A case study of Saguenay, Quebec (Canada). Waste Management, 77, 341-349.

Guermoud, N., Ouadjnia, F., Abdelmalek, F., et al. (2009). Municipal solid waste in Mostaganem city (Western Algeria). Waste Management, 29, 896-902.

Halstenberg, F. A., Chen, E. Y., Rumpel, G., et al. (2018). An efficiency-oriented batch reduction procedure for hazardous material. Procedia Manufacturing, 21, 822-829.

Han, Z. Y., Fei, Y. Q., Liu, D., et al. (2017). Yield and physical characteristic analysis of domestic waste in rural areas of China and its disposal proposal. Transactions of the Chinese society of Agricultural Engineering, 33, 1-14. (in Chinese).

Han, Z., Liu, Y., Zhong, M., et al. (2018). Influencing factors of domestic waste characteristics in rural areas of developing countries. Waste Management, 72, 45-54.

Hassan, T., Zahra, A., Hassan, A., et al. (2016). Characterizing and quantifying solid waste of rural communities. Journal of Material Cycles and Waste Management, 18, 790-797.

Hla, S. S., \& Daniel, R. (2015). Characterisation of chemical composition and energy content of green waste and municipal solid waste from Greater Brisbane, Australia. Waste Management, 41, 12-19.

Hou, D., Abir, A. T., Peter, G., et al. (2012). Sustainable waste and materials management: National policy andglobal perspective. Environment Science \& Technology, 46, 2494-2495. 
Huerta-Pujol, O., Soliva, M., Giró, F., et al. (2010). Heavy metal content in rubbish bags used for separate collection of biowaste. Waste Management, 30, 1450-1456.

Islam, K. M. N. (2018). Municipal solid waste to energy generation: An approach for enhancing climatecobenefits in the urban areas of Bangladesh. Renewable and Sustainable Energy Reviews, 81, 2472-2486.

Komilis, D., Evangelou, A., Giannakis, G., et al. (2012). Revisiting the elemental composition and the calorific value of the organic fraction of municipal solid wastes. Waste Management, 32, 372-381.

Komilis, D., Kissas, K., \& Symeonidis, A. (2014). Effect of organic matter and moisture on the calorific value of solid wastes: An update of the Tanner diagram. Waste Management, 34, 249-255.

Kumar, K. N., \& Goel, S. (2009). Characterization of municipal solid waste (MSW) and a proposed management plan for Kharagpur, West Bengal, India. Resources, Conservation and Recycling, 53, 166-174.

Li, Z. L., Yue, B., Gong, X. F., et al. (2017). Comparision of physical and chemical properties of rural domestic garbage from villages and towns in spring, China. Environment Engineering, 11, 1787-1794. (in Chinese).

Maulini-Duran, C., Artola, A., Font, X., et al. (2014). Gaseous emissions in municipal wastes composting: Effect of the bulking agent. Bioresource Technology, 172, 260-268.

Mufeed, S., Kafeel, A., Gauhar, M., et al. (2008). Municipal solid waste management in Indian cities-A review. Waste Management, 28, 459-467.

Muralikrishna, I. V., \& Manickam, V. (2017). Chapter Seventeen-Hazardous waste management. In Environmental Management (pp. 463-494). Butterworth-Heinemann.

NBSC (China National Bureau of Statistic). (2017). China statistical yearbook. China Statistics Press, Beijing. http://www.stats.gov.cn/.

(PRC) The People's Republic of China (2017). Ministry of Housing and Urban-Rural Development of the People's Republic of China. http://www.mohurd.gov.cn/.

Rafiee, A., Elham, G., Lu, W. J., et al. (2018). The impact of various festivals and events on recycling potential of municipal solid waste in Tehran, Iran. Journal of Cleaner Production, 183, 77-86.

Ren, Y., Yu, M., Wu, C., et al. (2018). A comprehensive review on food waste anaerobic digestion: Research updates and tendencies. Bioresource Technology, 247, 1069-1076.

Sha'Ato, R., Aboho, S. Y., Oketund, F. O., et al. (2007). Survey of solid waste generation and composition in a rapidly growing urban area in Central Nigeria. Waste Management, 27, 352-358.

VIP Chinese Science and Technology Internet. (2019). http://www.cqvip.com/.

Thi, N. B. D., Kumar, G., \& Liu, C. Y. (2015). An overview of food waste management in developing countries: Current status and future perspective. Journal of Environment Management, 157, 220-229.

Tian, H. Z., Gao, J. J., Long, L., et al. (2012). Temporal trends and spatial variation characteristics of hazardous air pollutant emission inventory from municipal solid waste incineration in China. Environment Science \& Technology, 46, 10364-10371.

Yue, B., Zhang, Z. B., Sun, Y. J., et al. (2013). Characteristics of rural household solid wastes in Chin. Environment Science \& Technology, 37, 129-134. (in Chinese).

Zhang, H. Y., Li, G. X., Gu, J., et al. (2016). Influence of aeration on volatile sulfur compounds (VSC s $_{\text {) }}$ and $\mathrm{NH}_{3}$ emissions during aerobic composting of kitchen waste. Waste Management, 58, 369-375.

Zhang, L., \& Sun, X. (2016). Improving green waste composting by addition of sugarcane bagase and exhausted grape marc. Bioresource Technology, 218, 335-343.

Publisher's Note Springer Nature remains neutral with regard to jurisdictional claims in published maps and institutional affiliations. 